\title{
LIMITES E POSSIBILIDADES DE UMA PEDAGOGIA PARA A MODERNIDADE LÍQUIDA
}

\author{
Solange Franci Raimundo Yaegashi ${ }^{1}$ \\ Robson Borges Maia ${ }^{2}$ \\ Teresa Kazuko Teruya ${ }^{3}$ \\ Luciana Maria Caetano ${ }^{4}$ \\ Luciane Guimarães Batistella Bianchini ${ }^{5}$
}

\section{RESUMO}

Este trabalho, de caráter teórico descritivo, tem como objetivo identificar as características que uma teoria pedagógica deve ter para atender às demandas que recaem sobre a educação escolar. Para tanto, analisamos as principais mudanças que ocorreram nas práticas pedagógicas durante o século XX e refletimos sobre o momento histórico em que vivemos para identificar a pedagogia que desponta na nossa sociedade. Concluímos que momentos de crise são também geradores de novas oportunidades e apontamos uma série de qualidades indispensáveis às teorias pedagógicas do século XXI amparados na leitura de Bauman sobre a modernidade líquida.

Palavras-chave: Teorias Pedagógicas; Pedagogia; Modernidade líquida.

\section{LIMITS AND POSSIBILITIES OF A PEDAGOGY FOR THE LIQUID MODERNITY}

\begin{abstract}
The main aim of this theoretical-descriptive work is to identify the characteristics that a pedagogical theory must be to meet the demands which fall on the school education. Therefore, we analyzed the main changes that occurred in the pedagogical practice during the twentieth century and reflected about the historical moment we live in, in order to identify the pedagogy that rises over our society. We concluded that moments of crisis are also generators of new opportunities and we pointed some indispensable qualities to the pedagogical theories from the twenty-first century, supported by Bauman's views about the liquid modernity.
\end{abstract}

Keywords: Pedagogical Theories; Pedagogy; Liquid Modernity.

\section{Introdução}

O acelerado desenvolvimento científico e tecnológico das últimas décadas trouxe vários benefícios e facilidades para a vida em sociedade. No entanto, esses avanços vêm promovendo transformações sociais tão velozes e profundas que têm deixado as nossas instituições com uma sensação de desorientação pela incapacidade de assimilar o ritmo das mudanças e pela perda dos referenciais culturais estabelecidos.

No interior de nossa própria cultura, sem sair de nossa própria cidade nem de nosso próprio bairro, um belo dia observamos nosso ambiente e nos damos conta de que tudo mudou tanto que mal somos capazes de saber como as coisas funcionam. Sentimo-nos, então, desorientados, tão desorientados como se tivéssemos viajado para uma sociedade estranha e distante, mas sem esperança de voltar a recuperar aquele ambiente 
conhecido no qual sabíamos nos arranjar sem problemas (ESTEVE, 2004, p. 24).

Estamos no meio da travessia de um modelo societário a outro, e como bem pondera Marcondes (1996, p. 29), "o verdadeiro sentido do momento pelo qual estamos passando só pode ser estabelecido e avaliado a posteriori, em retrospecto, quando e se, de acordo com a terminologia de Kuhn, se instaura um novo contexto de normalidade".

A escola, como uma das principais instituições da nossa sociedade, não ficou imune a essas mudanças. Ela busca reinventar-se, reconstruir-se, redefinir-se no seu o papel social em um mundo em que quase tudo ao redor é mais interessante que a sala de aula. Não só os conteúdos (o que ensinar) estão sendo questionados, mas também os métodos (como ensinar) encontram-se no centro das discussões sobre o futuro da educação escolar.

É nessa busca que analisamos e refletimos sobre as principais teorias pedagógicas do século XX para responder ao seguinte problema de pesquisa: que características deve ter uma teoria pedagógica para atender às demandas que recaem sobre a educação escolar no século em que vivemos?

Essa problemática é investigada tendo como referência as obras de autores contemporâneos como Harvey e Bauman, que apesar de não elegerem como objeto de análise central em suas obras a educação escolar, nos auxilia nessa tarefa de caráter teórico descritivo. Portanto, nosso objetivo é identificar as características que uma teoria pedagógica deve ter para atender às demandas da escola da modernidade líquida, como Bauman (2010) denomina o nosso momento histórico. Para isso, analisamos as principais mudanças que ocorreram nas práticas pedagógicas durante o século $\mathrm{XX}$, elencando algumas características fundamentais de cada uma dessas práticas por entendermos ser indispensável para a compreensão do nosso objeto de estudo.

Em seguida, refletimos sobre o momento histórico em que vivemos, em um esforço para identificar como deveria ser a pedagogia mais adequada para esse início de século, cientes de que mudanças profundas deverão ocorrer se a escola quiser sobreviver como instituição responsável pela formação das novas gerações.

$\mathrm{Na}$ conclusão, discorremos acerca da importância dos momentos de crise como geradores de novas oportunidades, a partir das quais podemos transformar a atual realidade educacional.

\section{As principais teorias pedagógicas do século $\mathrm{XX}$}

No dicionário Houaiss (2015, s/p) consta que pedagogia é um substantivo feminino, introduzido em nossa língua em 1813, com o significado de "ciência que trata da educação dos jovens, que estuda os problemas relacionados com o seu desenvolvimento como um todo". Por extensão de sentido, a pedagogia é o "conjunto de métodos que asseguram a adaptação recíproca do conteúdo informativo aos indivíduos que se deseja formar".

Esmiuçando essa última definição, aprofundamos nossa reflexão sobre os termos indivíduo e conteúdo informativo. Ambos os termos transformam-se a cada nova geração. Um saber que era útil e indispensável em um determinado momento do nosso processo civilizatório pode perder completamente sua utilidade e importância em outro momento. No tocante ao indivíduo, temos consciência de que cada período da história demanda um indivíduo específico, formado em consonância com os valores e as necessidades predominantes em seu tempo e espaço social.

Etimologicamente, pedagogia vem do grego paidogogós, junção de paidós (criança) com agogós (guia, condutor). Paidogogós era, portanto, o escravo que 
acompanhava a criança à escola. Esse termo "assumiu posteriormente conotações abstratas para indicar as teorias sobre a educação" (ARANHA, 2006, p. 34), que se materializa no ato pedagógico, definido por Libâneo (1985) como uma atividade sistemática de interação entre seres sociais, visando a mudanças tão eficazes que os tornem elementos ativos dessa própria ação exercida.

$\mathrm{O}$ ato pedagógico é uma especificidade do ato comunicativo e, como tal, é composto necessariamente por três elementos: o agente emissor que ensina, que pode ser o professor ou a professora, um grupo ou a comunidade; a mensagem a ser transmitida, que pode ter cunho cognitivo, afetivo ou motor; e a pessoa receptora, ou seja, o aluno ou a aluna, uma turma em uma sala de aula e até mesmo toda uma geração. Por essa razão, as teorias pedagógicas só podem ser compreendidas em um determinado contexto sócio histórico, posto que é uma característica das sociedades humanas a transformação no transcorrer do tempo (ARANHA, 2006).

Tendo o ato pedagógico como referência, neste tópico analisamos as principais teorias pedagógicas do período republicano do Brasil, focando nossa atenção nas características da relação entre docente e discente desse período por entendermos que a compreensão histórica das mudanças que se deram nessa relação é o primeiro passo para a recuperação da nossa memória sobre a função social da escola.

\section{A pedagogia tradicional}

O Brasil República, nascido no final do século XIX, iniciou uma gradativa passagem do modelo agrário-exportador para o modelo urbano-exportador. Nessa fase, surgia nos países centrais da Europa a escola pública, laica, gratuita e universal, com a finalidade de implantar um sistema de crenças e valores adequados à sociedade industrial.

Criada para suprir as necessidades da organização produtiva industrial, a escola tornou-se também uma necessidade social e um meio para disseminar a visão burguesa do mundo e assim consolidar a burguesia industrial como classe dominante. O conhecimento deveria então ser transmitido por meio da escola e aqueles que se apropriassem do conteúdo escolar estariam aptos a viver em uma sociedade em que a prosperidade e a riqueza estariam diretamente relacionadas à posse e aplicação dos conteúdos escolares.

Segundo Saviani (1987), a concepção filosófica de educação predominante nesse período foi a concepção "humanista" tradicional, que vê a educação como algo tributário de determinado "sistema filosófico" geral. Havia uma visão essencialista de ser humano, tido como possuidor de uma essência imutável. De acordo com essa concepção, a educação deveria conformar-se à essência humana, pois nela não havia lugar para a inovação.

A escola tradicional no Brasil inspirou-se na pedagogia do filósofo alemão Johann Friedrich Herbart (1776 - 1841) e do educador suíço Johann Heinrich Pestalozzi (1746 1827). A extensa literatura herbartiana, publicada nos EUA, chegou ao Brasil na transição do século XIX para o século XX por intermédio de intelectuais ligados às oligarquias dirigentes e à Igreja (GHIRALDELLI JUNIOR, 1994).

Acoplada ao culto, ao rigor, à disciplina, à forma e à organização curricular oriunda do positivismo e do iluminismo, a pedagogia herbartiana forneceu o corpo principal do que chamamos hoje no Brasil de escola tradicional (GHIRALDELLI JUNIOR, 1994). Nesse período, a educação era concebida como instrução, caracterizada pela transmissão de conhecimentos a ser realizada única e exclusivamente na e pela escola. O conhecimento provinha do meio e deveria ser transmitido ao indivíduo na escola pelo método herbartiano dos cinco passos: preparação, apresentação, associação, generalização e aplicação. As 
diferenças individuais não eram respeitadas, porque buscava a padronização do conhecimento e a homogeneização das condutas.

Conforme Hilgenheger (2010), na escola inspirada em Herbart, o ensino era centrado no professor e voltava-se para o que era externo ao aluno tais como o programa e as disciplinas. A relação na sala de aula ocorria de forma vertical, cabendo ao professor a decisão sobre o que, quando e como ensinar, com o predomínio do autoritarismo e do distanciamento. Aos alunos cabiam apenas executar a determinação do professor, de modo obediente e passivo.

Freire (1987), no livro Pedagogia do Oprimido, escrito em 1968 durante seu exílio no Chile, chamou de "educação bancária" esse modelo de ensino em que o aluno e a aluna eram concebidos como uma "caixa" de depósito. Nessa concepção, o professor ou a professora depositava o conhecimento no aluno. Quanto maior a quantidade de conteúdos depositados, melhor seria o ensino, já que o aluno ou a aluna teria uma educação melhor com a cabeça cheia de conhecimentos adquiridos na instituição escolar. Desse modo, a formação escolar assegurava a permanência de posições fixas. O professor ou a professora era a pessoa detentora do saber, enquanto o aluno ou a aluna deveria aprender.

Fernández Enguita (2004) aponta que na escola tradicional a criança aprendia, de modo sistemático, uma série de novidades tendo sempre em vista a adaptação à nova ordem social eminentemente industrial. Para inserir-se na sociedade na nova ordem era preciso submeter-se a uma autoridade impessoal e burocrática; aceitar que outros decidissem por elas o que fazer, como fazer, quando e em que ritmo; competir de maneira destrutiva; aceitar uma estrutura social desigual e estratificada; manter uma atividade regular e continuada independentemente de seu estado de ânimo e desenvolver novos hábitos de conduta. Essas eram algumas das características das relações sociais que se davam na escola e que expressavam, até certo ponto, as relações sociais próprias da sociedade industrial.

Entretanto, novas necessidades sociais foram surgindo, a partir das quais novas formas de trabalho e novas instituições foram sendo inventadas. No Brasil, a república velha agonizava. Enquanto nos países desenvolvidos a segunda revolução industrial caminhava a pleno vapor, nosso país ainda não havia concluído a passagem do modelo agrário-exportador para o modelo industrial urbano-exportador. Na década de 1920 educadores pátrios iniciam um movimento na tentativa de criar um sistema educacional para a Nação, que até então era considerado inorganizado, fato que marcou o início de um novo momento na história das tendências pedagógicas em terras brasileiras.

\section{A pedagogia escolanovista}

Inspirado na obra do filósofo norte-americano John Dewey (1859-1952), foi publicado o Manifesto dos Pioneiros da Educação Nova em 1932, tendo como principais signatários Fernando de Azevedo, Anísio Teixeira e Lourenço Filho, dentre um total de 26 educadores. A educação brasileira passou a viver um clima de grandes expectativas, decorrentes das mudanças que se operavam nos campos político, econômico e cultural. Discorrendo sobre este Manifesto de 1932, Aranha (2006) lembra que em um mundo marcado por profundas transformações, a função da escola era preparar o indivíduo para uma sociedade dinâmica.

O movimento educacional conhecido como Escola Nova surgiu no final do século XIX justamente para propor novos caminhos à educação, em descompasso com o mundo no qual se achava inserida. Representa o 
esforço da superação da pedagogia da essência pela pedagogia da existência (ARANHA, 2006, p. 225).

Dewey se opôs à pedagogia tradicional, dentre outras razões, por ela não relacionar as disciplinas do programa de estudos com os interesses da criança (WESTBROOK, 2010).

Dewey pedia aos educadores que integrassem a Psicologia ao programa de estudos, construindo um ambiente em que as atividades imediatas dos alunos se confrontem com situações problemáticas que exijam conhecimentos teóricos e práticos da esfera científica, históricos e artísticos, para resolvê-las (WESTBROOK, 2010, p. 18).

Para Saviani (1987), a concepção filosófica de educação que se encontra na base do chamado movimento da escola nova é a concepção "humanista" moderna, que abrange, dentre outras correntes, o pragmatismo, o historicismo, o existencialismo e a fenomenologia. A concepção humanista moderna é centrada na existência, que precede a essência e dá à natureza humana um caráter mutável. O ser humano é complexo e inacabado, por isso o ensino é centrado no aprendiz e não em quem ensina, como na concepção tradicional. Ao invés de seguir uma ordem lógica, segue uma ordem psicológica. Ao invés de subordinar os meios aos fins, subordina os fins aos meios.

A escola nova concebe a educação em seu sentido mais amplo, como formação humana e não apenas como a educação que se processa na escola. A educação tem por fim a "aprendizagem que abranja conceitos e experiências, tendo como pressuposto um processo de aprendizagem pessoal" (MIZUKAMI, 1986, p. 45). A escola decorrente de tal concepção coloca o aprendiz no centro do processo de ensino e de aprendizagem, razão pela qual:

Essa abordagem dá ênfase às relações interpessoais e ao crescimento que delas resulta, centrado no desenvolvimento do indivíduo, em seus processos de construção e organização pessoal da realidade, e em sua capacidade de atuar, como uma pessoa integrada. Dá-se igualmente ênfase à vida psicológica e emocional do indivíduo e à preocupação com a sua orientação interna, com o autoconceito, com o desenvolvimento de uma visão autêntica de si mesmo, orientada para a realidade individual e grupal (MIZUKAMI,1986, p. 37-38).

Na relação pedagógica que se estabelece na sala de aula, o papel da docência é o de "facilitar a aprendizagem", possibilitando o contato com as dificuldades existenciais e individuais. Assim, o relacionamento no espaço escolar prioriza a construção de um ambiente democrático e acolhedor, onde o professor ou a professora trabalha com as características individuais de cada aprendiz. Este, por seu turno, desempenha o papel central no processo de ensino e de aprendizagem, razão pela qual essa pedagogia é considerada pedocêntrica (ARANHA, 2006).

Quem aprende é um sujeito ativo e tem a responsabilidade pelo aprendizado que se dá pela descoberta. Assim, cada aprendiz se desenvolve de acordo com suas próprias capacidades e recursos em função da sua ação e esforço individual. "O diretivismo no ensino, característico das abordagens predecessoras, é aqui substituído pelo nãodiretivismo: as relações verticais e impostas, por relação EU-TU e nunca EU-ISTO" (MIZUKAMI, 1986, p. 31).

\section{A pedagogia tecnicista}


Três décadas após a publicação do Manifesto dos Pioneiros da Educação Nova, o Brasil passou por outro golpe de Estado, dado em 1964 pelos militares, que modificou radicalmente a estrutura e o funcionamento da educação pátria. A partir dessa década, a educação brasileira conheceria a pedagogia tecnicista, inspirada na teoria do condicionamento operante do psicólogo norte-americano Burrhus Frederic Skinner (19041990). Para ele, a educação, o processo de ensino e aprendizagem e a instrução significam arranjos de contingências que possibilitam a transmissão cultural, fim último de todo o processo educacional (MIZUKAMI, 1986).

Ressalvamos, todavia, que no Brasil, a passagem do paradigma escolanovista para o tecnicismo não ocorreu única e exclusivamente por força do regime militar. Nos países centrais, um novo modo de produção surgia, determinando novas formas de trabalho e, consequentemente, dando origem a novos moldes de relacionamento humano. Na segunda metade do século XX, o mundo desenvolvido viu nascer o modelo de produção e de sociedade que Harvey (1992) denominou condição pós-moderna e Bauman (2010; 2013) modernidade líquida.

Deste modo, educação escolar brasileira foi redirecionada para uma concepção de ensino que enfatizava a organização racional dos métodos pedagógicos, privilegiando os processos metodológicos em detrimento da própria aquisição do conhecimento que se dá pela aprendizagem.

O pressuposto que embasou esta pedagogia está na neutralidade científica, inspirada nos princípios de racionalidade, eficiência e produtividade. Buscou-se a objetivação do trabalho pedagógico da mesma maneira que ocorreu no trabalho fabril. Instalou-se na escola a divisão do trabalho sob a justificativa de produtividade, propiciando a fragmentação do processo e, com isso, acentuando as distâncias entre quem planeja e quem executa (VEIGA, 1989, p. 34-35).

De acordo com Saviani (1987), a escola tecnicista está relacionada à concepção analítica de Filosofia da Educação, a qual não pressupõe explicitamente uma visão de homem nem um sistema filosófico geral. Na concepção analítica, a tarefa da Filosofia da Educação é efetivar a análise lógica da linguagem educacional pela lógica informal. Não é tarefa sua produzir enunciados e muito menos práticas.

Corroborando Veiga (1989), a escola tecnicista se caracteriza por uma excessiva preocupação com a eficácia e a eficiência do processo de ensino, razão pela qual os aspectos mensuráveis e observáveis são extremamente valorizados. Toda estratégia de ensino deve ser fundamentada nos princípios da tecnologia educacional. Assim, o ensino compõe-se de padrões de comportamento que podem ser mudados por meio de condicionamentos baseados em categorias de comportamento e em habilidades a serem desenvolvidas.

Para Saviani (1985, p.15), a escola tecnicista se propôs a "planejar a educação de modo a dotá-la de uma organização radical capaz de minimizar as interferências subjetivas que pudessem pôr em risco sua eficiência". Nessa perspectiva, o elemento fundamental da escola tecnicista passa a ser a organização racional dos meios, ao contrário da escola tradicional, que tinha no professor ou na professora o elemento central do processo de ensino e de aprendizagem, e da escola nova, na qual o aprendiz ocupava a posição central nesse processo.

Mizukami (1986, p.31) assinala que na pedagogia tecnicista "o professor [ou a professora] teria a responsabilidade de planejar e desenvolver o sistema de ensino- 
aprendizagem, de forma tal que o desempenho do aluno [ou da aluna] seja maximizado, considerando-se igualmente fatores tais como economia de tempo, esforços e custos".

O trabalho docente passa a ser considerado, por conseguinte, um trabalho de engenharia comportamental, capaz de arranjar as contingências de reforço de modo a possibilitar a ocorrência de uma resposta a ser aprendida. $\mathrm{O}$ aluno e a aluna submetem-se ao que foi racionalmente planejado para obter a resposta desejada. É um mero expectador da realidade objetiva, já que a aprendizagem decorre da aquisição dos comportamentos desejáveis. Exigem-se respostas prontas e corretas, o que o torna condicionado e acrítico.

Em suma, nessa concepção de escola o relacionamento docente-discente fica em segundo plano, pois ambos deixam de ser os elementos fundamentais do processo de ensino e de aprendizagem. Na escola tecnicista, "o processo é que define o que professores [professoras] e alunos [alunas] devem fazer, quando e como o farão" (VEIGA, 1989, p. $35)$.

Os defensores do tecnicismo argumentavam que:

O país deveria fazer progredir a qualidade da mão-de-obra nacional através de uma rede de ensino voltada para a capacitação técnica do trabalhador [e da trabalhadora]. Cada homem [cada mulher], uma vez tendo aumentado o seu "capital humano" - sua capacitação técnica de trabalho especializado -, poderia produzir mais e melhor e contribuir de maneira mais efetiva para o desenvolvimento econômico do país (GHIRALDELLI JUNIOR, 1994, p. 186).

Com essa pedagogia, o regime militar reduziu a educação a mero fator econômico de produção, dirigida aos interesses do capital. A escola tecnicista tinha a função de formar indivíduos para o sistema produtivo, perdendo de vista a especificidade da ação educativa. A pedagogia tecnicista, portanto, almejava uma formação acrítica e eficaz para tornar indivíduos condicionados, pois ao trabalho docente competia apenas seguir à risca as recomendações dos manuais e dos livros didáticos. Por fim, esse esforço educacional consistia em desenvolver a competência técnica do aluno e da aluna.

\section{As pedagogias libertadora e histórico-crítica}

No final da década de 70 do século XX, organizava-se no Brasil uma concepção de educação que postulava a superação das desigualdades sociais a partir das contradições presentes no modo de produção flexível. Tal concepção foi representada pela Pedagogia Libertadora e pela Pedagogia Histórico-Crítica, que tiveram como principais expoentes Paulo Freire e Dermeval Saviani.

Essas correntes pedagógicas, colocadas na clandestinidade pelo regime militar, só se tornaram conhecidas do grande público a partir da década de 80 do século XX, graças aos movimentos sociais que pediram o fim ditadura, que já durava duas décadas. Síntese de diversas correntes de pensamentos, tais como o humanismo, a fenomenologia, $\mathrm{o}$ existencialismo e o marxismo, essas pedagogias procuraram elaborar uma proposta de educação que se tornasse, para as camadas dominadas da sociedade, instrumento útil na luta pelas transformações sociais e projetassem uma sociedade cada vez menos desigual e mais inclusiva.

Assim, a concepção dialética de educação escolar busca

[...] superar o intelectualismo formal do enfoque tradicional, evitar os efeitos do espontaneísmo escolanovista, combater a orientação 
desmobilizadora do tecnicismo e recuperar as tarefas especificamente pedagógicas, desprestigiadas a partir do discurso reprodutivista. Procura ainda, compreender e analisar a realidade social onde está inserida a escola (VEIGA, 1989, p. 39-40, grifos nossos).

Adentramos, portanto, no século XXI recriando a nossa ordem social transformada pelas décadas de regime militar, enquanto Europa, Japão e Estados Unidos já se rendiam à flexibilização da produção. Era preciso, mais uma vez, encontrar uma pedagogia que atendesse aos novos ditames do paradigma flexível. Do currículo aos métodos pedagógicos, da estrutura e organização do ensino à formação de professores e professoras, tudo precisava ser repensado para acompanhar as profundas transformações sociais impostas pelo novo modo de produção como o toyotismo.

Convém ressaltar que as pedagogias descritas neste tópico não se sucederam de modo linear, como afirma Saviani (1987). Em pleno século XXI, encontramos na escola brasileira traços da pedagogia tradicional, influências escolanovistas e práticas educativas inspiradas no tecnicismo, todas com algo em comum: nenhuma delas isoladamente serve à nova realidade social desenhada pela modernidade líquida (BAUMAN, 2013), como abordaremos no tópico a seguir.

\section{O século XXI e a busca por uma nova pedagogia}

O ponto de partida de uma teoria pedagógica é sempre um problema apresentado pela realidade educacional, que por sua vez reflete a realidade social, afirma Aranha (2006). Uma pedagogia para a escola do século XXI exige, antes de tudo, compreender e refletir sobre a contemporaneidade. Para realizar essa tarefa, ancoramos nossos estudos nas ciências humanas auxiliares da educação, mais precisamente as obras de Harvey (1992) e Bauman (2008; 2010; 2013), salientando que este último propõe uma leitura sociológica da nossa sociedade pela qual é possível inferir como se encontra a nossa educação.

Harvey (1992) sustenta que a condição pós-moderna, sob a égide do padrão de acumulação flexível, articula um conjunto de elementos de continuidade e descontinuidade, criando algo distinto do padrão taylorista/fordista de acumulação, mas retendo o caráter essencialmente capitalista do modo de produção vigente e de seus pilares fundamentais. Segundo o autor, o toyotismo propõe um confronto direto com a rigidez do fordismo por meio da flexibilidade dos processos de trabalho, dos mercados de trabalho, dos produtos e padrões de consumo. A acumulação flexível foi acompanhada na ponta do consumo por uma atenção muito maior às modas fugazes e pela mobilização de todos os artifícios de indução de necessidades e de transformação cultural que isso implica.

Bauman $(2008 ; 2010 ; 2013)$ complementa essa concepção sustentando que novos valores, novas necessidades, novas lógicas operacionais, novos gostos e sentidos, novas formas de consumo e de gozo do tempo livre e até mesmo novas personalidades são algumas das novidades surgidas na modernidade líquida, com a velocidade dos mais modernos processadores de dados e informações.

Assim, tanto a condição pós-moderna de Harvey (1992) quanto a modernidade líquida de Bauman (2013) são expressões usadas para se referirem ao nosso tempo, caracterizado pela sensação cada vez maior de que a nossa realidade contemporânea é leve, fluida, instantânea, volátil e flexível. Justamente por força dessas características a nossa realidade é também imprevisível, instável, descartável, passível de rápidas e profundas transformações. A modernidade líquida, no pensamento de Bauman (2013), refere-se a uma civilização do excesso, do dejeto e do seu descarte. Ao contrário da modernidade 
sólida, construída sobre valores perenes e imutáveis, a sociedade em que vivemos valoriza o provisório e o imediato.

A vida líquido-moderna nos instiga ao constante movimento e à busca por novidades, de modo a evitar que qualquer coisa praticada no momento se transforme em hábito. A modernidade líquida nos impõe a libertação do legado do próprio passado para usarmos a "identidade atual como uma camisa que pode ser prontamente substituída quando sai de moda, desdenhar das velhas lições e das antigas habilidades sem inibição ou remorso" (BAUMAN, 2013, p. 36). A solidez das coisas e dos vínculos humanos é vista como ameaça. "Qualquer compromisso a longo prazo prenuncia um futuro prenhe de obrigações que limitam a liberdade de movimento e a capacidade de perceber novas oportunidades assim que elas se apresentarem" (BAUMAN, 2010, p. 40).

Isso dificulta sobremaneira o advento de uma nova teoria pedagógica, caracterizando aquilo que denominamos no presente trabalho de "limites" de uma pedagogia para a modernidade líquida. Bauman (2013) sustenta que o nosso mundo líquido exige que as pessoas esqueçam hoje o que aprenderam ontem e aprendam hoje o que devem esquecer amanhã.

Os limites de uma pedagogia para a modernidade líquida residem na constatação de que os fins da educação escolar na contemporaneidade são questionados, os valores subjacentes ao processo educacional são postos em xeque, as forças sociais que estruturam a escola na atualidade são voláteis e efêmeras, o papel dos atores da educação escolar se intercambia, de modo a impossibilitar uma definição precisa dos mesmos, os espaços e os tempos educacionais se transformam com tal velocidade que impede aos sujeitos da educação apreender os sentidos dessas mudanças. Tudo isso resulta num inevitável sentimento de impotência diante do desafio de pensar uma pedagogia que sirva à essa nova realidade.

Teorizar sobre métodos que buscam a adaptação recíproca do conteúdo informativo aos indivíduos que se deseja formar significa também, conforme Bauman (2008, p. 177):

Teorizar um processo formativo que não é guiado desde o princípio pela forma do alvo projetada de antemão; moldar sem conhecer ou visualizar claramente o modelo a ser atingido; um processo que pode, na melhor das hipóteses, sugerir, nunca impor, seus resultados e que constrói essa limitação em sua própria estrutura; em resumo, um processo com final aberto, mais preocupado em permanecer assim do que com qualquer resultado específico.

No entanto, Bauman (2013) não se mostra pessimista ou paralisado frente a esses limites. Quando reflete sobre o futuro do sistema educacional usa a figura dos mísseis inteligentes em oposição aos mísseis balísticos, como metáfora para as possibilidades de uma pedagogia para a modernidade líquida. Os mísseis balísticos eram as armas ideais nas guerras de posição, com alvos imóveis, visto que aprendiam antes de serem lançados e jamais se esqueciam. O que aprendiam era para toda a vida, como de fato acontecia nas relações de aprendizagem na modernidade sólida. Já os mísseis inteligentes são as armas do momento, usados para alvos móveis, razão pela qual aprendem no percurso e esquecem com rapidez. O conhecimento que adquirem é eminentemente descartável, semelhante ao que ocorre nas relações de aprendizagem da modernidade líquida.

Complementando esse raciocínio, Bauman $(2013$, p. 17) cita a teoria dos três níveis de aprendizagem, postulada por Gregory Bateson (1904-1980): 
O nível mais baixo é a transferência de informação a ser memorizada. O segundo, a "deuteroaprendizagem", visa ao domínio de uma "estrutura cognitiva" à qual a informação adquirida ou encontrada no futuro possa ser absorvida e incorporada. Mas há também um terceiro nível, que expressa a capacidade de desmontar e reorganizar a estrutura cognitiva anterior ou desembaraçar-se totalmente dela, sem um elemento substituto.

O terceiro nível se transformou em uma norma no processo de ensino e aprendizagem da modernidade líquida e vem impondo uma revisão radical da estrutura cognitiva do sujeito que aprende. Trata-se, por conseguinte, de um momento revolucionário, de uma crise paradigmática que "tem pouco a ver com as faltas, os erros e a negligência dos pedagogos profissionais, tampouco com os fracassos da teoria educacional" (BAUMAN, 2008, p. 163).

Há motivos para preocupação, mas não para desespero. Todo e qualquer processo de construção cultural resulta da combinação do destino e do caráter, de modo que o ser humano é o responsável pela construção do seu presente e do seu futuro. "O destino delineia o conjunto de opções viáveis, mas é o caráter que as seleciona, escolhendo algumas e rejeitando outras. Não há situação que não contenha mais de uma opção" (BAUMAN, 2013, p. 27). Não existe, portanto, situação sem escolha.

Bauman (2013) adverte que, para fazermos uso adequado da liberdade de escolha, precisamos ter consciência das possibilidades oferecidas pelo destino e do conjunto de ações alternativas dentre as quais escolher. Se o principal propósito da escolarização é preparar as gerações vindouras para as realidades que tenderão a enfrentar, uma pedagogia para o século XXI, deve cultivar, dentre outras coisas, na visão de Bauman (2008, p. 176177):

\begin{abstract}
A capacidade de conviver em paz com a incerteza e a ambivalência, com uma variedade de pontos de vista e com a ausência de autoridades confiáveis e infalíveis; deve significar tolerância em relação à diferença e vontade de respeitar o direito de ser diferente; deve significar fortalecer as faculdades críticas e autocríticas e a coragem necessária para assumir a responsabilidade pelas escolhas de cada um e suas consequências; deve significar treinar a capacidade de "mudar os marcos" e de resistir à tentação de fugir da liberdade, pois com a ansiedade da indecisão ela traz também as alegrias do novo e do inexplorado.
\end{abstract}

A realidade social analisada e discutida neste tópico nos mostrou os principais problemas da escolarização na modernidade líquida, a partir dos quais podemos pensar alternativas pedagógicas. Esse é o primeiro passo para a construção de uma pedagogia, a partir do qual podemos refletir sobre as possibilidades de estabelecer objetivos realizáveis, buscar os meios para atingi-los, verificar sua eficácia e rever os processos utilizados na transmissão do legado cultural às gerações vindouras, sempre com a finalidade de aperfeiçoá-los.

\title{
Conclusão
}

As pedagogias predominantes no século XX, que nos forneceram diferentes possibilidades de educação escolar, já não servem mais, fato que dificulta (ou até mesmo inviabiliza) o trabalho de transmissão do legado cultural da humanidade às gerações mais novas. 
Exatamente na medida em que não mais podemos identificar um paradigma dominante em nosso contexto de pensamento - referência básica para nossos projetos científicos, políticos, éticos, pedagógicos e mesmo estéticos - é que nos caracterizamos como vivendo uma crise de paradigmas, e até mesmo uma crise da própria necessidade e possibilidade de um paradigma hegemônico (MARCONDES, 1996, p. 28, grifo nosso).

Por outro lado, aprendemos com a história que períodos de crise são extremamente férteis para a sociedade, pois nesses períodos reconhecemos os limites e criamos novas possibilidades de enfrentamento da realidade, por meio das quais podemos discutir uma nova pedagogia para a educação escolar da modernidade líquida.

Nosso objetivo, com o presente estudo, foi identificar as características que uma teoria pedagógica deve ter para atender às demandas que recaem sobre a escola no momento histórico em que vivemos. Tal pesquisa bibliográfica, de caráter teóricodescritivo, permite-nos concluir que, de acordo com Bauman (2008, 2010, 2013), na modernidade líquida qualquer proposta pedagógica, para ser possível e viável, precisa desenvolver no aprendiz a capacidade de conviver em paz com a incerteza e a ambivalência. Precisa também desenvolver o senso de tolerância e respeito às diferenças em um mundo em que as autoridades são cada vez menos confiáveis e as lideranças cada vez mais falíveis. A pedagogia do século XXI precisa fortalecer o senso crítico do aprendiz para proporcionar a capacidade de assumir a responsabilidade por suas escolhas e as consequências pelos próprios atos. Por fim, a pedagogia da modernidade líquida precisa desenvolver a habilidade de resistir à tentação de fugir da liberdade.

Estes são os fundamentos de uma pedagogia para a modernidade líquida, com os seus limites e suas possibilidades. Tais fundamentos revelam os desafios que a educação escolar tem pela frente, caso queira continuar existindo como uma instituição fundamental para a formação das gerações vindouras. A nossa expectativa é de que este trabalho possa inspirar investigações mais profundas e consistentes acerca da problemática aqui discutida.

Cientes de que não há espaço para pessimismo ou imobilismo, e independentemente das adversidades impostas pela modernidade líquida, a educação escolar terá que ser reinventada para estar a serviço da nova sociedade que emerge no seio da velha ordem até então dominante, tendo sempre em mente que é pela escola que precisamos recomeçar.

\section{Referências}

ARANHA, Maria Lúcia de Arruda. Filosofia da Educação. São Paulo: Moderna, 2006.

BAUMAN, Zigmunt. A sociedade individualizada: vidas contadas e histórias vividas. Rio de Janeiro: Jorge Zahar, 2008.

BAUMAN, Zigmunt. Capitalismo parasitário e outros temas contemporâneos. Rio de Janeiro: Jorge Zahar, 2010.

BAUMAN, Zigmunt. Sobre educação e juventude: conversas com Ricardo Mazzeo. Rio de Janeiro: Jorge Zahar, 2013.

ESTEVE, José Manuel. A terceira revolução educacional: a educação na sociedade do conhecimento. São Paulo: Moderna, 2004. 
FERNÁNDES ENGUITA, Mariano. Educar em tempos incertos. Porto Alegre: Artmed, 2004.

FREIRE, Paulo. Pedagogia do oprimido. Rio de Janeiro: Paz e Terra, 1987.

GHIRALDELLI JUNIOR, Paulo. História da Educação. São Paulo: Cortez, 1994.

HARVEY, David. Condição pós-moderna: uma pesquisa sobre as origens da mudança cultural. São Paulo: Loyola, 1992.

HILGENHEGER, Norbert. Johann Herbart. Recife: Fundação Joaquim Nabuco, Editora Massangana, 2010.

HOUAISS, Antonio. Grande Dicionário Houaiss da Língua Portuguesa. Disponível em:〈http://houaiss.uol.com.br/>. Acesso em: 15 ago, 2015.

LIBÂNEO, José Carlos. Democratização da escola pública: a pedagogia crítico-social dos conteúdos. São Paulo: Loyola, 1985.

MARCONDES, Danilo. A crise dos paradigmas e o surgimento da modernidade. In: BRANDÃO, Zaia. A crise dos paradigmas e a educação. São Paulo: Cortez, 1996.p. 1429.

MIZUKAMI, Maria da Graça Nicoletti. Ensino: as abordagens do processo. São Paulo: Epu, 1986.

SAVIANI, Dermeval. Escola e democracia. São Paulo: Cortez, 1985.

SAVIANI, Dermeval. Tendências e correntes da educação brasileira. In: BOSI, Alfredo. et al. Filosofia da educação brasileira. Rio de Janeiro: Civilização Brasileira, 1987.

SAVIANI, Dermeval. Pedagogia Histórico-Crítica: primeiras aproximações. Campinas, SP: Cortez-Autores Associados, 2005.

VEIGA, Ilma Passos de Alencastro. Repensando a didática. Campinas: Papirus, 1989.

WESTBROOK, Robert Brett. John Dewey. Recife: Fundação Joaquim Nabuco, Editora Massangana, 2010.

Notas

\footnotetext{
${ }^{1}$ Doutora em Educação pela Universidade Estadual de Campinas. Docente da Universidade Estadual de Maringá. Contato: solangefry@gmail.com

${ }^{2}$ Doutorando em Educação pela Universidade Estadual de Maringá. Docente da UNICESUMAR. Contato: rb-maia@uol.com.br

3 Doutora em Educação pela Universidade Estadual Paulista Júlio de Mesquita Filho. Docente da Universidade Estadual de Maringá. Contato: tkteruya@gmail.com

${ }^{4}$ Doutora em Psicologia Escolar e do Desenvolvimento Humano pela Universidade de São Paulo. Docente do Instituto de Psicologia da Universidade de São Paulo. Contato: lmcaetano@usp.br

5 Doutora em Psicologia pela Universidade Estadual Paulista Júlio de Mesquita Filho. Docente da Universidade Estadual de Londrina e da UNOPAR. Contato: luannbi@hotmail.com
}

Recebido: $\quad$ março/16 Aprovado: dezembro/16 